\title{
MIGRATING FROM A LEGACY ENTERPRISE RESOURCE PLANNING (ERP) SYSTEM TO A NEW ERP SYSTEM: A CASE STUDY
}

\author{
S.V.Doddaiah ${ }^{1}$, S.B.Mallur ${ }^{2}$, Aravindrao.M.Yadwad ${ }^{3}$ \\ ${ }^{1}$ Research scholar, Visvesvaraya Technological University “Jnana sangama”, Belgaum-590018, Karnataka State, India, \\ ${ }^{2}$ Professor, Department of Mechanical Engineering, UBDT collage of Engineering, Davangere -577001. Karnataka \\ State, India, \\ ${ }^{3}$ Associate Professor, Department of Mech. Engg. National institute of Engineering, Mysore -570008. Karnataka State, \\ India,
}

\begin{abstract}
Abstract: Enterprise resource planning (ERP) systems are software packages, integrates different functions, facilitates information flow, equipped with standard practices are the latest Information technology tools for effective business management of large, small and medium scale enterprises. Even after four decades since their inception, developed and reached a level of what they are today are imperfect and not sufficient enough to satisfy the overall expectations of an organization. Like anything else ERP systems are also tends to become obsolete and less effective with age. As the business process evolve over the time and if the ERP system is static and no longer support the strategic plan of the organization, if older ERP vendor is out of business, legacy ERP system has been customized over customized many times over the years, replacing an ERP system is an opportunity to refine, simplify or expand the functionality of the organization. As part of our research work, by taking as a case study, this paper describes the implementation experience of an ERP system for the first time in an organization and after some years of use, they are replacing the existing one with the new ERP system to expand their business market globally. This paper also describes reasons for replacement, the features, impacts / benefits, cost of ownership, change management of new system and other related issues.
\end{abstract}

Keywords: ERP, Legacy system, change management, SAP.

\section{HISTORY OF ERP SYSTEM}

The term ERP was coined in 1990 by Gartner's group but history starts from

1960: As early computers, reorder point (ROP) systems and early material requirements planning (MRP)

1970: As MRP and computer hardware and software development.

1980: As MRP II (Manufacturing resource planning)

1990: As MRP II and early ERP systems.

2000: As extended ERP $\{1\}$

Extended ERP ( $\left.\mathrm{E}^{2} \mathrm{RP}\right)$ is boundary less, modules like customer relationship management (CRM), Supplier relationship management (SRM) facilitates the organization to integrate with external stake holders such as customers, suppliers, venders and bankers. Today ERP has extended to encompass business intelligence (BI) tool which helps in taking meaningful decisions. Throughout the world large, midsize and small companies rapidly adopting ERP systems. Software as a Service (SaaS) Solutions- Also referred to as Cloud Computing helped this growth. Cloud based solutions not only make ERP software more affordable may also make these systems easier to implement and manage. As a result, companies of all sizes and a wide range of industries are transporting to cloud ERP systems. In fact it is predicted that SaaS based ERP adoption will Rise $21 \%$ annually through 2015.

\subsection{ERP Research Related Issue}

Since the study of ERP system is a new area, limited studies have been conducted in the past but now due to development of ERP market, the need for more studies is important [2]. Even with the continuous effort and contribution of many researchers as ERP research field is evolving and developing continuously research in the ERP area is still lacking and the gap in the ERP literature is large [3].

In reviewing ERP research two distinct research streams emerges one, concept oriented, focuses on the corporate capabilities and the second one as system oriented, focuses on the details associated with implementing ERP systems and their impacts, success and cost[4].

It is necessary to investigate further that enhances our understanding of issues involved in implementing these complex systems and provide helps to develop implementation strategies that lead to success. [5] 


\subsection{ERP Life Cycle:}

ERP life cycle frame work is structured in phases \& dimensions. The phases are the different stages of an ERP system life cycle within an organization and dimensions are the different viewpoints by which the phases could be analyzed [2]

The two distinct phases of ERP have been identified. The first phase refers to the changes that an organization undergoes in transforming from the old system and going live with the ERP system. The second phase also called the second value of ERP refers to the actions subsequent to ERP implementation that enable the organization to achieve the full capabilities and benefits of ERP [6].

Setting the enterprise into the enterprise system:

Before implementing an ERP system the organization must have clear cut strategies, must change organizational structure not just computer systems. An enterprise system imposes its own logic on a company's strategies culture and organization. Those companies that stressed the enterprise not the system gained the greatest benefits [7].

Implementing ERP systems is an expensive and time consuming project. A substantial cost is associated with preimplementation involvement and training designed to encourage acceptance of effective implementation of the ERP system [8]

ERP can provide significant improvement and efficiency across a company but only when implemented correctly [13], otherwise an ERP system could be curse \& drag the whole Enterprise into inefficiency, planning for ERP system and their implementation requires an integrated approach to meet the various demands of functional areas [9]. ERP systems are complex information systems the implementation of these systems is a difficult task [15]

\subsection{Critical Success Factors}

It is necessary to examine the following important factors that to a great extent determine whether the implementation will be successful or not.

Clear understanding of strategic goals

Commitment by top management

Excellent project management

A great implementation team

Organizational change management

Data accuracy

Extensive education and training

Focused performance measures [15]

Successful ERP implementation often requires the identification and management of the above Essential Factors [10],[11]

\subsection{ERP Implementation Characteristics:}

Implementation of an ERP system is generally a formidable challenge with a typical ERP implementation taking anywhere from one year to two years.

Some companies have had very successful implementations while others have struggled [12]. Over last decade our world has changed dramatically due to growing phenomenon of globalization and revolution in information technology. There is tremendous demand on companies to lower the cost, improve product quality and provide reliable delivery details through effective co-ordination of production and distribution activities. To change these goals company must continuously change or re-engineering their business practices and employ new Information systems [14].

\subsection{ERP in Different Manufacturing Organizations:}

Different organizations in different countries have been implementing different ERP systems for different business reasons. The previous studies about ERP systems from different countries will provide some key insights into the implementation and use of ERP systems in different manufacturing sectors. Swedish manufacturing firms broadly adopting ERP systems, 83.6\% have implemented such systems or are in the process of implementing. Swedish firms often choose to implement ERP systems from Swedish vendors [16]. The study from US manufacturing firms shows that size of the organization is a key factor in the implementation approach for companywide systems [17]. The study from Canadian organizations reveals that each adopting organization has a distinct set of objectives for implementing ERP systems. [18]. The study from Denmark shows that ERP system can be seen as an organizational actor in its own right as it is a large extent influence values, culture, behavior, processes and procedures of other actors in the organization [19]. The study from China industries shows that some Chinese specific difficulties in the implementation process and provide solutions to implement ERP systems successfully [20]. Study from Korean manufacturing firms helps to compare adoption ERP systems, motivation, Implementation strategies and benefits to compare with other countries [21].

\subsection{ERP Performance Measurement:}

To Measure the performance of an ERP system a balanced scorecard, a frame work originally developed in order to structure the performance measurement of an ERP System is used for evaluating the ERP projects [23], [24], Another important validated measurement model and instrument for assessing ERPs success from multiple Perspectives was developed and the above model employees twenty seven measurements of the four dimensions, information quality, system quality, individual impact and organization Impact [25]. 


\subsection{Benefits of ERP:}

A Comprehensive frame work suggested by the author [22],[26].,assessing the benefits of ERP system, the suggested frame work tries to classify the types of benefits as

Operational benefits.

Managerial benefits.

Strategic benefits.

IT Infrastructure benefits.

Organizational benefits.

ERP implementation will bring both tangible and intangible benefits for the organization. Author suggested useful framework for assessing the following benefits of ERP, Once the ERP reaches its maturity level. Analysis of benefits irrespective of its Size will help the other non adopters to think of whether to go for ERP or not

\section{METHODOLOGY}

As a part of our research work to explore more information and details about organizations ERP implementation experience, we selected an organization which has implemented, an ERP system for the first time and after some years of use, now they are changing their old ERP system with the new one for some business reasons.

For the present work, the required information was gathered through,

Personal interviews with the ERP mangers.

Company websites.

Company media coverage book (2012-2013).

\section{CASE STUDY - N RANGA RAO AND SONS}

\subsection{Improving Quality of Life; the Secrets of Success}

In a span of over sixty years, at the beginning is fledging cottage industry developing art of making incense. Today is a global enterprise leading in the refined art of incense making Rang Rao and sons, the renowned fragrance makers from Mysore are the market leader in India, with their flagship brand in cycle pure agarbathies and also a major exporter. Along the way integrated to cover all aspects of the fragrance creation chain .Thus transcending from being an incense company to one that provides the complete range of solutions in air care, from deodorants to aroma oils from room fresheners to perfumes and from fragranced life style products to botanical research and floored extracts. The first company to put the humble agarbathies on the commercial group of India.

\subsection{Group of Companies:}

N Rang Rao and Sons (1948)

Rangsons Marketing Services Pvt. Ltd. (1993 )

Rangsons Electronics Pvt. Ltd (1993).

Ripple Fragrance Pvt. Ltd (2005).
N Rang Rao and Sons and Exports (1979)

Natural and Essential Oils Pvt. Ltd.

\subsection{Products}

Incense, Personal care, Aircare, Export range, Life style, Electronics, Natural extracts, Fragrant candles. While many Indian family owned enterprises carry the reputation of having short term visions there are some that are futuristic building their legacy and charting a success story in the process. Established in 1948 as Mysore Products And General Trading Company, Head Quartered in Mysore, Karnataka state India founded by late Sri N.Rang rao as an agarbathie (incense) manufacturing company initially a family enterprises but the group of companies now have independent corporate setup currently managing by third generations as CEOs. The exports divisions' exports incense and related products to more than fifty countries in Asia, Africa, Latin America, The Middle East For East Of North America.

\section{VISION AND MISSION}

Satisfaction consumer needs and wants through systematic and regular customer services.

In 2000-domestic incense industry size (manufacturing side) was estimated at Rs. 500 crore and exports 100 core. The current market value 1500 crore domestic and Rs 350 crores (export).

Our challenge is to Nurture the existing business and start new ones. The market is nascent and we are at the right place at the right time.

Arjun Ranga CEO

Cycle Pure Agarbathie

ERP SUCCESS STORY: Discussions were held with IT and ERP managers to know about the details of First ERP system selection, reasons for selection, pre implementation, implementation and post implementation, training, Impact, Benefits, cost and also reasons for replacing the existing ERP related issues

Before implementing ERP system in their organization, Tally was used; to overcome the limitations of the legacy system in the year of 2007 they decided to go with an ERP systemMicrosoft Navision for the first time. The implementing partners were ABS, Bangalore. Finance, Purchase, Sales, Warehouse, Quality, and Production were the different modules implemented with the total number of 90 licenses. HR module was not implemented. It was expected to complete the whole project within 8-9 months, but actual time taken was 18 months and completed in the year 2009. Total cost of the project was 1.5 crores. The project team was consists of people from Top management (5) key users (20) and IT persons. There was a minor customization with major process re engineering for finance module, for production module 
major customization with minor process re engineering. No customization for purchase, sales and quality modules. While implementing, resistance from end users and change management were the key issues.

The benefits from ERP system were integration of information, reduced cycle time, overall organizational growth. As there is no fixed rule for assessing return on investment (ROI), no attempt was made to measure the same. Even with experience of success with the first ERP systems due to some limitations, as Microsoft Navision cannot handle data beyond certain size, it cannot take more MIS (Management information system) load, to overcome these limitations from the year 2014 they decided to go for change, to implement new (Second) ERP system- SAP, PWC are the implementing partners located at Bangalore. The total cost of the project would be rupees 3.5 crores. All formalities to implement the new ERP is completed and it is about to start the implementation work as early as possible.

Ms. Anitha, IT ERP manager

\section{CONCLUSIONS}

There are many reasons to migrating an existing ERP systems, one of the hard realities that many enterprises are no longer keep with their new business models, existing ERP systems no longer support the strategic plan of the organizations, many of the legacy systems were customized and implemented do not possess required agility to meet the customer demands also they are not customer centric, many legacy ERP systems are not capable of keeping up with the information needs of the modern business enterprises.

To meet the strategies of the business organizations and expectations of customers a new approach, a new ERP systems are designed implemented and used.

\section{REFERENCES}

[1]. F Robert Jocobs, F.C 'Ted ' Weston Jr ,Decenber 2006 Enterprise resource Planning.(ERP); A brief history.

[2]. Jose M Esteves, Joan A . Pastor, 1999, An ERP life cycle based research agenda.

[3]. Majed Al- Mashari, 2003, Enterprise resource Planning.(ERP) systems: Research agenda.

[4]. F Robert Jocobs, Elliot Bendoly, 2003, Enterprise Resource Planning: Developments and Directions For Operations Management Research.

[5]. Toni M Somers, Klara Nelson, Arik Ragowsky ,2000, Enterprise Resource Planning For The Next Millennium: Development of an Integrative Frame Work and Implications for Research.

[6]. T. Hillman Willis, Ann Hillary Willis-Brown, 2002, Extending the value for ERP.

[7]. Thomas H. Davenport, 1998, Putting the enterprise into the enterprise system.
[8]. Sue Abdinnour- Helm, Mark L Lengnick-Hall, Cynthia A lengnick -hall, 2003,Pre Implementation Attitudes and Organizational Readiness For Implementing an Enterprise Resource Planning System.

[9]. Purnendu Mandal, A Gunasekaran, 2003, Issues In Implementing ERP: A case Study.

[10]. Majed Al- Mashari, Abdulla Al-Mudimigh, Mohammed Zairi, 2003, Enterprise Resource Planning: Taxonomy of Critical Factors.

[11]. T.C Loh And S.C.L Koh, September 2004, Critical Elements For A Successful Enterprise Resource Planning Implementation In Small And Medium Sized Enterprises.

[12]. Vincent A Mabert, Ashok Sony, M A Venkataramanan, 2003, Enterprise Resource Planning-Managing the Implementation Process.

[13]. Jai Deep Motwani, Dinesh Mirchandani, Manu Madan, A Gunashekaran, 2002, Successful Implementation Of ERP Projects: Evidence From Two Case Studies.

[14]. Mahesh Guptha, Amarpreet Kohli, 2006, Enterprise Resource Planning Systems and Its Implications For Operations Functions.

[15]. Elisabeth J Umble, Ronald R Haft, M Michael Umble,2003, Enterprise Resource Planning: Implementation Procedures and Critical Success Factors.

[16]. Jan Olhager,Eric Selldin, 2003 Enterprise Resource Planning Survey of Swedish Manufacturing Firms.

[17]. Vincent A Mabert, Ashok Sony, M A Venkataramanan, 2003, The Impact of Organization Size on Enterprise Resource Planning Implementation In The US Manufacturing Sectors.

[18]. Vinod Kumar, Bharath Maheshwari, Umakumar 2002, ERP System Implementation: Best Practices In Canadian Govt Organizations.

[19]. Pall Rkhardsson, Parnille Kraemmergaard,2005, Identifying The Effects of Enterprise System Implementation And Use: Example From Denmark.

[20]. Yahaya Yusaf, Aangappa Gunashekaran,Canglin Wu,2006, Implementation of Enterprise Resource Planning In China.

[21]. Taehyung Lee, Young B Moon, Heeseok Lee, 2006, Enterprise Resource Planning Survey of Korean Manufacturing Firms.

[22]. Shari Shang, Peter B Seddom, 1995,A Comprehensive Frame For The Classifying The Benefits For Enterprise Resource Planning System.

[23]. Michael Rosemann, Jens Wiese, 1999, Measuring the Performance of ERP Software-A Balanced Scorecard Approach

[24]. Donald Chand, George Hachhey, James Hunto, Vincent Owhoso, Sri Vasudevan,2005. A Balanced Scorecard Based Frame Work For Assessing The Strategic Impacts of ERP Systems.

[25]. Guy G. Gable, Darshana Sedera And Taizan Chan, 2000, Enterprise Systems Success: A Measurement Model.

[26]. Daniele.O'leary, 2004, Enterprise Recourse Planning (ERP) Systems: An Empirical Analysis of Benefits. 